\title{
Comparison of Perinatal Outcome of Breech Presentation between Vaginal Delivery and Cesarean Section
}

\author{
Buddhi Kumar Shrestha, ${ }^{\mathrm{a}, \mathrm{c}}$ Subha Shrestha ${ }^{\mathrm{b}, \mathrm{c}}$
}

\begin{abstract}
:
Introduction: Many times, parturient opt for labour and vaginal breech delivery even after informing increased perinatal risks. Vaginal breech deliveries are undertaken with the reasons like avoidance of cesarean section in next pregnancy, null risk of operative and anesthetic hazards, ability to resume early all household works after vaginal birth, etc. The purpose of this study is to compare the perinatal outcome of breech deliveries in singleton breech presentation between vaginal breech delivery and cesarean section. Methods: A retrospective study was done in Lumbini Medical College Teaching Hospital for the duration of one year (December 2014 to November 2015). Data of perinatal outcome of breech deliveries were collected from the hospital records. The records of neonatal examination were also collected. The primary outcomes included were neonatal morbidity and mortality. Results: Out of 80 selected women with breech presentation, 42 of them had vaginal deliveries and 38 women had undergone caesarean section. The perinatal mortality was $4.8 \%$ and morbidity was $2 \%$ in vaginal breech deliveries. There was no significant difference of APGAR score in the two groups at any time. Similarly, there was no significant difference in perinatal morbidity and mortality in the two groups. Nulliparous women were more likely to deliver by cesarean section. Conclusion: In places where planned vaginal delivery is a common practice and when strict criteria are met before and during labour, planned vaginal breech delivery of singleton fetus in breech presentation remains a safe option that can be offered to women.
\end{abstract}

Keywords: breech presentation • cesarean section • perinatal mortality • pregnancy outcome $\bullet$ vaginal birth

\section{INTRODUCTION:}

Breech presentation is defined as a fetus in longitudinal lie with the buttocks or legs adjacent to the birth canal (cervix) or enters it near term before the head. It occurs in 3-4\% of all deliveries. ${ }^{1}$ Predisposing factors for breech presentation includes prematurity, uterine anomalies, fetal hydrocephalus,

a - Assistant Professor

b - Lecturer

c - Department of Obstetric and Gynecology,

Lumbini Medical College Teaching Hospital, Palpa, Nepal

Corresponding Author:

Dr. Buddhi Kumar Shrestha

e-mail: drbuddhi205@gmail.com

How to cite this article:

Shrestha BK, Shrestha S. Comparison of perinatal outcome of breech presentation between vaginal delivery and cesarean section. Journal of Lumbini Medical College. 2016;4(1):4-6. doi: 10.22502/jlmc.v4i1.87. space occupying lesion in lower pole of uterus, etc. There is a lot of controversy regarding selection of candidate for trial of vaginal breech delivery.

American College of Obstetricians and Gynecologists (ACOG) and Royal College of Obstetrician and Gynecologists (RCOG) recommend that "the decision regarding the mode of delivery should depend on the experience of the health care provider" as a multicenter trial showed that planned cesarean delivery was not associated with a reduction in the rate of death or developmental delay. The perinatal mortality and morbidity increases with breech presentation by 2-4 folds regardless of the mode of deliveries. In short, decision of mode of breech deliveries should be individualized. ${ }^{1}$

There is no enough evidence regarding the use of planned caesarean delivery for preterm or term babies. ${ }^{2,3}$ 
The current study is an attempt to compare the perinatal outcome between vaginal breech deliveries and caesarean breech deliveries.

\section{METHODS:}

A retrospective study was done in Lumbini Medical College Teaching Hospital for the duration of one year (December 2014 to November 2015) comprising of 80 cases of breech presentation delivered after 28 completed weeks of gestation.

All women with breech deliveries and 28 completed weeks of gestation during the period of study were included. Following were excluded from the study: congenital anomalies incompatible to vaginal delivery, any breech other than frank and complete breech (footling breech presentation, hyperflexed head), intrauterine fetal death, multiple pregnancies, clinically inadequate pelvis, macrosomia, or Intra Uterine Growth Retardation (IUGR) baby.

Outcome measures studied were: neonatal mortality and morbidities (need of NICU, fractures, paralysis, respiratory distress syndrome, cord prolapse and one minute APGAR score less than five).

Data were collected and entered in Excel 2007. Analysis was done with SPSS 16. Descriptive statistics like mean, standard deviation, frequency, percentage were calculated. Pearson chi square test was used for comparison and $p$ value $<0.05$ was considered significant.

\section{RESULTS:}

There were total 3160 deliveries during the study period. Among them, 80 women had breech presentation and hence the rate of breech presentation was $2.53 \%$. Caesarean section was done in $38(47.5 \%)$ women out of which elective was done in $8(10 \%)$ and emergency in $30(37.5 \%)$ cases. Vaginal breech delivery was conducted in 42 (52.5\%).

Of those 80 breech, 48 (60\%) were frank breech and the rest 32 (40\%) were complete breech. Vaginal breech deliveries were common in frank breech $(n=36,75 \%)$ and cesarean section was common in complete breech $(n=26,81 \%)$ and this difference was statistically significant $X^{2}(N=80$, $d f=1)=24.4, p<0.001$. Thus, the women with frank breech were more likely to deliver by vaginal route.

APGAR score of babies at one and five minutes is shown in Table 1. There was no significant difference of APGAR score in two groups at any time. Perinatal morbidity and mortality in the two groups is compared in Table 2 and Table 3 . There is no significant difference in perinatal morbidity and mortality in the two groups.

Relationship between mode of delivery was compared to parity of the women. There were 46 nulliparous and 34 multipara women. Among nulliparous, $30 \quad(65 \%)$ delivered by cesarean section whereas among multipara, only eight (24\%) delivered by cesarean section. This difference was statistically significant $\left(X^{2}[N=80, d f=1]=13.6\right.$, $p<0.001)$. Nulliparous women were more likely to deliver by cesarean section.

\begin{tabular}{rccccc}
\begin{tabular}{l} 
Table 1: APGAR score by mode of delivery \\
\hline $\begin{array}{c}\text { Apgar } \\
\text { Score }\end{array}$
\end{tabular} & $\begin{array}{c}\text { Vaginal delivery } \\
(N=42)\end{array}$ & $\begin{array}{c}\text { Cesarean section } \\
(N=38)\end{array}$ & \\
\hline & $n$ & $\%$ & $n$ & $\%$ & \\
\hline $\begin{array}{r}1 \mathrm{~min} \\
<7\end{array}$ & 3 & 7.1 & 3 & $7.8 \%$ & $p=1$ \\
$>7$ & 39 & 92.9 & 35 & $92.2 \%$ & $F E T$ \\
$5 \mathrm{~min}$ & & & & & \\
$<7$ & 2 & 4.7 & 2 & $5.3 \%$ & $p=1$ \\
$>7$ & 40 & 95.3 & 36 & $94.7 \%$ & $F E T$ \\
\hline
\end{tabular}

Table 2: Perinatal morbidity by mode of delivery

\begin{tabular}{lccccc}
\hline & $\begin{array}{c}\text { Vaginal } \\
\text { delivery } \\
(N=42)\end{array}$ & $\begin{array}{c}\text { Cesarean } \\
\text { section } \\
(N=38)\end{array}$ & \\
\hline Morbidity & $n$ & $\%$ & $n$ & $\%$ & \\
Present & 2 & & 2 & & \\
\multicolumn{1}{c}{ Birth asphyxia } & 2 & 4.7 & 0 & & $p=1$ \\
$\quad$ Meconium aspiration & 0 & & 2 & 5.2 & $F E T$ \\
Absent & 40 & & 36 & & \\
\hline
\end{tabular}

Table 3: Perinatal mortality by mode of delivery

\begin{tabular}{cccccc}
\hline & $\begin{array}{c}\text { Vaginal delivery } \\
(N=42)\end{array}$ & $\begin{array}{c}\text { Cesarean section } \\
(N=38)\end{array}$ & \\
\hline Death & $n$ & $\%$ & $n$ & $\%$ & \\
Present & 1 & 2.3 & 1 & 2.6 & $p=1$ \\
Absent & 41 & 97.7 & 37 & 97.4 & FET \\
\hline
\end{tabular}

\section{DISCUSSION:}

There is a risk that reduction in vaginal breech deliveries may lead to less skilled obstetricians and less favorable results in situations where vaginal delivery is unavoidable, such as undiagnosed breech in advanced labor or delivery of second twin. So, a skilled practitioner should be available to conduct 
labour with breech presentation and all vaginal breech deliveries. Where such facility is lacking, a lady should be optioned/referred to the better center. Practitioner should have appropriate training like Advance Life Support training in Obstetrics (ALSO), skilled birth attendant (SBA) to supervise labour and delivery of breech and should be readily available. $^{4}$

Planned vaginal delivery of singleton fetuses in breech presentation at term remains a safe option that can be offered to women in places where vaginal delivery is a common practice and when strict criteria are met before and during labor, planned considering the type of breech, pelvic adequacy and estimated fetal weight etc. ${ }^{5}$

Perinatal mortality and morbidity rate reduction is possible when all women begin to value preconception counseling and attendance at antenatal clinics. ${ }^{6}$ Many authors, in their study, had concluded term vaginal breech delivery is associated with significantly increase in perinatal morbidity and mortality (more evident in nullipara women and in neonates with expected birth weight 3500-4000 g), when compared with caesarean breech delivery. ${ }^{7,8,9,10,11}$ On contrary, our study had resulted similar outcomes on perinatal mortality and morbidity in breech delivery by vaginal route or by cesarean Section.

Haider S., in her study had concluded that there is no firm evidence to support systemic elective cesarean section for all breech presentation at term. To determine whether a potential benefit for the neonates out-weight the increased risk to mother after elective caesarean section, large unbiased studies are needed. ${ }^{12}$

In countries like ours, women prefer to have vaginal birth due to fear of surgery, physical restrain that has to be maintained post operation, need of repeated sections in future pregnancies, financial status, etc. We could not oblige all parturient for elective cesarean section when many studies and RCOG guideline recommend vaginal breech deliveries by trained practitioners. In our institute, practitioners with ALSO training, SBA training are conducting vaginal breech deliveries for years under supervision of experienced obstetricians.

The PREMODA trial was conducted in France and Belgium and it did not find a significant excess risk associated with vaginal delivery compared with cesarean section. In the light of the PREMODA study, some obstetricians have been calling for a return to breech vaginal delivery. ${ }^{4}$

\section{CONCLUSION:}

With utmost respect to guidelines and evaluation of various factors leading to fetal morbidity and mortality from surgical procedure and anesthetic hazards as well as no difference in outcome of neonates regarding the route of deliveries; we prefer to provide supervised planned vaginal birth to the selected cases of breech presentation. In places where planned vaginal delivery is a common practice and when strict criteria are met before and during labour, planned vaginal breech delivery of singleton fetus in breech presentation remains a safe option that can be offered to women.

\section{REFERENCES:}

1. Williams JW. Breech Delivery. 24th ed. Cunningham FG, Leveno KJ, Bloom SL, Spong CY, Dashe JS, Hoffman BL, et al., editors. Williams Obstetrics. USA: McGraw Hill companies; 2014.558 p.

2. Alfirevic Z, Milan SJ, Livio S. Cesarean section versus vaginal delivery for preterm birth in singletons. Cochrane Database Syst Rev. 2012;6:CD000078.

3. Lindqvist A, Norden-Lindeberg S, Hanson U. Perinatal mortality and route of delivery in term breech presentations. Br J Obstet Gynaecol. 1997;104(11):1288-91.

4. Royal College of Obstetricians and Gynaecologists (2006) RCOG Guideline No. 20b Dec.

5. Goffinet F1, Carayol M, Foidart JM, Alexander S, Uzan $\mathrm{S}$, Subtil $\mathrm{D}$ et al. Is planned vaginal delivery for breech presentation at term still an option? Results of an observational prospective survey in France and Belgium. Am J Obstet Gynecol. 2006;194:1002-11.

6. Al-Mejhim FM,Al-NajashiSS. Trends in perinatal mortality at King Fahd Hospital of the University, Al-Khobar, Saudi Arabia: a ten years study. J Family Community Med. 1998; 5(2):31-7.

7. Alshaheen H, Abd Al-Karim A. Perinatal outcomes of singleton term breech deliveries in Basra. EMHJ. 2010; 16(1):34-9.

8. Hannah ME, Hannah WJ, Hewson SA, Hodnett ED, Saigal S, Willan AR. Planned caesarean section versus planned vaginal birth for breech presentation at term: a randomised multicentre trial. Term Breech Trial Collaborative Group. Lancet. 2000;356:1375-83.

9. Rietberg CC, Elferink-Stinkens PM, Brand R, van Loon AJ, Van Hemel OJ, Visser GH. Term breech presentation in The Netherlands from 1995 to 1999: mortality and morbidity in relation to the mode of delivery of 33824 infants. BJOG. 2003,110:604-60.

10. Rietberg CC, Elferink-Stinkens PM, Visser GH. The effect of the term breech trial on medical intervention behaviour and neonatal outcome in The Netherlands: an analysis of 35,453 term breech infants. BJOG. 2005;112:205-9.

11. Herbst A, Kallen K. Influence of mode of delivery on neonatal mortality and morbidity in spontaneous preterm breech delivery. Eur J Obstet Gynecol Reprod Biol. 2007;133: 5-9.

12. Herbst A, Thorngren-Jerneck K. Mode of delivery in breech presentation at term: increased neonatal morbidity with vaginal delivery. Acta Obstet Gynecol Scand. 2001; 80:731-7. 